\title{
The Influence of Aerobic Fitness on the Relationship between Academic Performance and Motor Proficiency
}

\author{
Ryan Alexander ${ }^{1, *}$, John A. Hay ${ }^{1}$, Jian Liu ${ }^{1}$, Brent E. Faught ${ }^{1}$, Joe Engemann ${ }^{1}$, John Cairney ${ }^{2}$ \\ ${ }^{1}$ Faculty of Applied Health Sciences, Brock University, Canada \\ ${ }^{2}$ Department of Family Medicine, McMaster University, Canada
}

Copyright $(\subset 2015$ by authors, all rights reserved. Authors agree that this article remains permanently open access under the terms of the Creative Commons Attribution License 4.0 International License

\begin{abstract}
Purpose: To determine whether physical fitness mediates the relationship between academic performance and motor proficiency in children. Methods: The academic achievement of 1864 students (F:926, M:938, age 11.91 (SD:0.34) from the Niagara Region of Ontario was derived from the average of provincial standardized tests for reading, writing, and mathematics. The Bruininks-Oseretsky Test of Motor Performance (short-form) determined motor proficiency. Fitness (peak oxygen uptake) was established with the 20-metre shuttle run multistage test. Results: Hierarchical linear modeling identified several significant predictors of academic performance. After controlling for age $(\mathrm{p}=0.7002)$, gender $(p<0.0001)$, and parental education $(p<0.0001)$, both motor proficiency $(p<0.0001)$ and physical fitness $(p=0.0004)$ remained significant. The addition of physical fitness to the model reduced the point estimate of motor proficiency from 0.004 to 0.003 , a reduction of $25 \%$. However, further examination of the $95 \%$ confidence intervals suggests that this reduction is not significant. Conclusions: These results suggest that aerobic fitness does not mediate the relationship between motor proficiency and academic performance. Both physical fitness and motor proficiency have independent roles in predicting academic performance.
\end{abstract}

Keywords Academic Performance, Physical Fitness, Physical Activity, Children, Motor Proficiency

\section{Introduction}

The many health benefits that accrue from a physically active lifestyle are well documented. As such, increasing physical activity has been the goal of numerous health promotion campaigns. Promoting physical activity among children is challenging, however one point of entry is the school environment.[1] In 2005, Canada's largest province by population introduced a policy, memorandum 138 , that required each child in a publicly funded elementary school to receive a minimum of 20 minutes of physical activity daily.[2] One significant challenge for the implementation of this and similar policies is the perception that increased time in physical activity during the school day will take away from school lessons and, as a result, diminish academic performance. Whether this perception holds in the face of scrutiny is unclear as the relationships between physical activity, physical fitness, and academic performance appear to be positive.

A number of studies have explored the relationship between physical activity and academic performance. Several indicated a positive relationship between academic performance and physical activity.[3,4] Results from experimental studies suggest that, at very least, increased time allocated to physical activity during school hours does not have a negative impact on a child's academic performance.[5,6] Physical activity and physical fitness are two different concepts, although it is generally accepted that increased activity is required to increase physical fitness.[7] A growing body of research demonstrates a positive association between physical fitness and academic performance. [8,9] This relationship is important as it allows a biologic rationale to be proposed for the association as it is postulated that increased blood flow and perfusion leads to greater neural development and capacity to learn, along with a psychological rationale in terms of increased focus and attention to task. There is an ongoing tension between the demands to increase the low levels of physical activity among Canadian children [10] and the increased emphasis placed on academic achievement. It is essential to gain a thorough understanding of the relationship among academic performance and physical fitness with an appreciation of children at greatest risk.

When considering children's physical activity, it is necessary to recognize that not all children are equally capable of pursuing physical activities. Between five and eight percent of children have significant motor impairments, making this subpopulation important to consider.[11] Children with poor motor competence have a significant activity deficit $[12,13]$ and weaker cardiorespiratory fitness 
relative to their peers. $[14,15]$ In addition, children with poor motor performance demonstrate academic difficulties in comparison to their peers even in the absence of known learning disabilities.[16,17] A coherent understanding of the complex association between physical fitness and academic performance requires an appreciation of the varied motor competencies of children. At this juncture little is known about the interrelationship of motor coordination, physical fitness, and academic performance. Motor proficiency is a significant predictor of both a child's academic performance and physical fitness. Meanwhile, physical fitness has been demonstrated as a significant predictor of academic performance. Neglecting to consider the potential role that physical fitness may have on the relationship between motor proficiency and academic performance prevents a full and thorough understanding of this association. The purpose of this study was to investigate the relationship between a child's motor proficiency and academic performance while determining the potential mediating role of aerobic fitness.

\section{Methods}

\section{Subjects}

This study examined cross-sectional data taken from a longitudinal, population-based, study. Details of the Physical Health Activity Study Team (PHAST) have been described in detail elsewhere.[18] All elementary schools in the District School Board of Niagara (DSBN) were eligible to participate in the study and 75 of 92 schools participated with informed parental consent obtained for 2278 of 2378 (95\%) eligible children. A total of 2141 students (1062 female subjects, 1079 male subjects) participated in Wave Three (2006) of the PHAST study when students were in Grade Six and motor performance measures were complete for all subjects. The PHAST study was not permitted to gather data pertaining to subject's ethnicity. However the DSBN has a marked homogeneity among its students with the large majority being Caucasian. According to Statistics Canada (2006), the total population of the Niagara region was 421,750 . Niagara's population was composed of 26,405 $(6.26 \%)$ visible minorities and 395,345 (93.74\%) were not visible minorities.[19]

\section{Measures}

The principal outcome variable in this study was academic performance measured using the Education Quality and Accountability Office's (EQAO) standardized tests. Each year every student enrolled in Grade Six in Ontario public schools must complete these tests which are administered at the same time throughout the province. The EQAO assesses students in an objective and reliable fashion in effort to enhance the quality and accountability of the education system in Ontario. Tests are scored by teams of certified Ontario teachers who pass a qualifier test to become an EQAO scorer. Scorers do not score entire booklets; rather they are assigned certain segments to help ensure consistency throughout the marking process. Booklets, labelled as validity papers, are pre-scored by "scoring leaders" and used to monitor both validity and reliability of each scorer.[20]

The test provides separate measures for reading, writing, and mathematics. For each test, a student's raw scores are converted to a scale score (range 0-4.9). Subjects are scored on a four point scale aligned with the Ontario Curriculum expectations. For this study an average EQAO score was calculated from the total scores on the three separate components of the EQAO test (reading, writing, and mathematics).

The Bruininks-Oseretsky Test of Motor Proficiency short form (BOTMP-SF) was used to determine motor proficiency. The BOTMP is one of the most common motor movement assessments in North America. The complete battery or long format (BOTMP-LF) consists of 46-items to assess children between 4.5 to 14.5 years old. The eight subtests within the short form provide an indication of a child's motor coordination. Four of the subtests evaluate gross motor skills, three measure fine motor skills, and one measures both gross and fine motor skills. The BOTMP-SF is comprised of 14 items selected from the complete battery and has been validated against the complete battery with inter-correlations between .90 and .91 for children ages 8 to 14.[21] The BOTMP-SF contains tasks such as heel-toe walking on a balance beam, two foot standing broad jump, copying shapes, timed pencil tapping in circles, clapping hands while jumping, and a 20 -meter sprint that assess a wide spectrum of representative motor abilities. The BOTMP-SF is desirable for studies with larger numbers of subjects as it takes approximately 30 minutes to administer as opposed to roughly two hours for the full BOTMP. Another desirable aspect of the BOTMP is that it does not require clinical experience to interpret the results and can be administered by trained research assistants. Finally, the BOTMP-SF has been suggested as a reasonable alternative to the $\mathrm{M}-\mathrm{ABC}$ when assessing motor impairment in children.[22]

The BOTMP-SF was administered to three randomly selected blocks of 25 schools over the first three waves of PHAST, until each of the participating 75 schools had been tested. Motor coordination remains consistent over time, making it reasonable to assess over different data-collection points.[23] Children in the first block of 25 schools $(\mathrm{N}=688)$ were screened in Fall 2005, the second group of students $(\mathrm{N}=723)$ was screened in Spring 2006, and the final group $(\mathrm{N}=672)$ was screened in Fall 2007. All research assistants attended a two hour training session to learn the proper procedures and protocols when administering the BOTMP-SF. The trainers leading these sessions, and the validity assessors remained the same during all three years. Within the schools, motor assessments were performed on an individual, distraction-free basis. Forms were scored by research assistants, excluding two fine motor tasks which were scored by a single experienced investigator, with $5 \%$ of these randomly selected for scoring by a second experienced assessor. 
Aerobic capacity was measured using the 20-metre shuttle run multistage test (20-MST).[24] The 20-MST has been validated as an appropriate predictor of a child's $\mathrm{VO}_{2}$ uptake.[25] Children and adolescents can reach exhaustion prior to achieving their full maximal oxygen uptake $\left(\mathrm{VO}_{2}\right.$ max), therefore peak oxygen uptake $\left(\mathrm{VO}_{2}\right.$ peak) is recognized as the criterion for aerobic fitness in youth.[26] The test requires subjects to run back and forth over a 20 metre span while keeping pace with a pre-recorded sound signal. Subjects are expected to continue until exhaustion, at which point the last stage completed is used to estimate aerobic capacity. The maximal speed $\left(\mathrm{km} \mathrm{h}^{-1}\right)$ attained during the last stage is used to calculate maximal oxygen uptake. For children, aerobic capacity can be estimated using the following equation: $\mathrm{VO}_{2}$ uptake $\left(\mathrm{ml} \cdot \mathrm{min}^{-1} \cdot \mathrm{kg}^{-1}\right)=31.025$ +3.238 (maximal speed, determined by stage completed) 3.248 (age, years) +0.1536 (speed $\mathrm{x}$ age).[27] Peak $\mathrm{VO}_{2}$ uptake was used as an indicator of cardiorespiratory fitness in this analysis.

Academic performance has a significant association with socioeconomic status (SES).[28] A proxy measure for SES, parental education, was collected through a questionnaire administered to the parent of each subject in Wave One. Parental education has been found to indirectly influence a child's academic performance.[29] The parent or primary guardian was asked the highest level of education that they had attained. Eight possible responses were provided: less than high school, high school (or GED), some college, trade certificate college, college, undergraduate degree (BA, BSc), professional degree (MD, LLB, BEng, MBA), and graduate degree (MA, PhD). Although not a direct measure of income, it provides a reasonable indicator of a child's SES.

\section{Data Analysis}

All statistical analysis was completed using Statistical Analysis Software (SAS) 9.2. Descriptive statistics were run by sex for all of the continuous variables under investigation: EQAO average, reading, writing, math, aerobic fitness, motor proficiency percentile, and age. Based on the design of the PHAST study, there is a natural clustering of children within schools which violates the assumption of statistical independence between observations required for OLS regression modeling. Although standardized testing should theoretically offer equal opportunity for every student, variation in results may exist depending on which school students attend. It is probable that students enrolled in a particular school are more similar to each other than a randomly selected group of students. Mixed modeling allows the variation between and within schools to be managed, something that OLS regression fails to accomplish. Therefore, hierarchical linear modelling was used to account for the random effect a student's school may have had on the relationship under investigation as OLS regression could result in biased standard errors, overly large test statistics, and inflated Type I error.[30]

\section{Results}

The original sample consisted of 2141 grade six students $(\mathrm{F}=912, \mathrm{M}=929)$ from 75 of 92 possible schools in the DSBN. After cleaning for missing and extreme values complete data was available for 1864 subjects. The mean age of the sample at time of testing was 11.90 years. Table 1 provides further descriptive information. Male and female subjects had a significant difference $(p<.0001)$ between their $\mathrm{VO}_{2}$ peak, BOTMP percentiles, reading, writing, and average EQAO scores.

To gain a better understanding of the relationship under investigation and to identify potential interactions, a visual representation is provided in Figures 1-2. EQAO scores were stratified by subject and examined relative to $\mathrm{VO}_{2}$ peak (Figure 1). Similarly, EQAO scores were stratified by subject and examined relative to BOTMP percentile (Figure 2). A clear relationship is readily apparent with academic performance increasing with both $\mathrm{VO}_{2}$ Peak and BOTMP Percentile.

Several predictive models were developed using hierarchical linear modelling. All variables were continuous apart from parental education and sex. The school attended by the child was treated as a random effect while all other variables in the analysis were kept as fixed effects. In Model 1 motor proficiency is a significant predictor of EQAO score while controlling for age, sex, and school. With the addition of aerobic fitness $(p<.0001)$ in Model 2, the coefficient for motor proficiency remains significantly related to overall academic performance but reduced by $25 \%$ from Model 1 (estimate $=.0003$, s.e. $=.0004, \mathrm{p}<.0001$ ). As seen in Figure 3, the $95 \%$ confidence intervals for the slope of motor proficiency overlap from Model 1 to Model 2. This suggests that the observed $25 \%$ reduction was not statistically significant and could be due to chance alone.

It should be noted that the addition of parental education in Model 3 reduces the sample size to 1179 as many families failed to complete this portion of data collection; therefore this was treated as a subsample. In Model 3, parent's education was added and the relationships remain positive. Both the within school variation (estimate $=.206$ ) and between school variation (estimate $=.023$ ) are significant when controlling for all other variables in the model. The variance component within schools was nearly nine times the size of the variance component between schools. Both aerobic fitness (estimate $=.011$ ) and motor proficiency (estimate $=.002$ ) significantly predict academic performance even after accounting for school effect and after controlling for all other variables, including parent education. The coefficients displayed in the fixed effects section of Table 2 can be interpreted in the same way as coefficients in OLS regression; they reflect the expected difference in the academic performance associated with a 1-unit change in the predictor variable. 


\section{Discussion}

The main objective of this study was to establish the relationship between motor proficiency and academic performance while determining the mediating effects of aerobic fitness. While the relationships between motor proficiency and academic performance, [16,17] between physical fitness and academic,[8] and between motor proficiency and physical fitness have been previously reported individually, $[14,15]$ the interrelationships between these three variables have not been investigated.

The findings from this study substantiate that a student's academic performance is significantly associated with motor proficiency. The results also support a growing body of evidence demonstrating a positive relationship between academic performance and aerobic fitness. It was originally hypothesized that poor physical fitness might account for much of the academic difficulties reported for children with motor impairments. Although a mediating relationship was originally anticipated, it became apparent that both aerobic fitness and motor proficiency have an independent role in predicting academic performance. Motor proficiency remained a significant predictor of academic performance even after controlling for age, sex, and SES, and accounting for random school effects. The significance of this finding should not be minimized. It can now be stated that lower academic performance among children with poor motor coordination is both present and not largely the result of lower fitness levels. Aerobic fitness and motor proficiency, although significantly associated, independently predict academic performance.

With physical fitness ruled out as a mediating variable, the discussion is open to other plausible reasons why motor proficiency predicts a child's academic performance. For example, children with motor difficulties have an increased time per stroke while handwriting when compared to their peers[31] and a link has been suggested between handwriting and academic performance.[32] If children have difficulty with the mechanics of writing and therefore maintaining pace with their classmates, the quality of their work may suffer providing an alternative explanation for the observed relationship between motor proficiency and academic performance.

Comorbidities may be another pathway by which the relationship between motor proficiency and academic performance may be explained. Research suggests that children with motor difficulties often concurrently have attention-deficit hyperactivity disorder (ADHD).[33,34] Children with ADHD perform lower academically than their peers. $[35,36]$ When trying to understand why children with motor deficits are outperformed academically by their peers, future research should compare the academic performance of children who have motor difficulties with and without ADHD. A probable explanation for this relationship extends to the child's social environment. A child's academic performance is influenced by their relations with peers and teachers.[37] The influence of social-motivation on academic motivation and the consequences for academic performance have been previously explored.[37] Students with low levels of motor coordination may experience social withdrawal. Children with movement difficulties are more likely to spend time alone, spend more time watching other children play and, at some ages, more likely to be disengaged from typical playground activities.[38] Boys with motor movement difficulties experience significantly higher loneliness compared to their counterparts without motor difficulties.[39] As children with motor difficulties experience higher levels of social isolation, there is reason to consider this as a mechanism for their academic struggles. The construct of social isolation may provide a partial explanation why certain children have difficulties academically.

Hierarchical linear modelling allowed the random effect that school may play to be controlled and it is noteworthy that both between and within school variation of academic performance was significant. Within school variation is expected as students within a school are anticipated to perform at varying levels. The observed variation between schools, which was nine times the variation within schools, is an important finding. Factors that contribute to variation of academic performance between schools should be further investigated. There may be lessons to be learned from understanding the environments and strategies of more successful schools. Providing equitable opportunities for students to meet their potential should be a priority for school boards.

\section{Limitations}

The results of this study should be considered in light of the following limitations. The cross-sectional design of this study limited its capacity to establish causation as it fails to track changes over a period of time. Therefore, whether motor proficiency causes academic performance or whether academic performance causes motor proficiency is not possible to determine, although only one direction is biologically plausible. Nevertheless, the cross-sectional nature of this study was able to identify significant associations between predictor and outcome variables.

A further limitation to this study is the fact that not all students completed the EQAO standardized grade six test. For reasons that cannot be determined, a small percentage $(\mathrm{N}=117)$ of students did not participate in testing. Perhaps these children were ill during the testing period, failed to properly complete the forms or, as is possible under very limited circumstances, students opted out of testing. Unfortunately one is left to speculate as to how these children may have impacted the results. Children who did not complete the EQAO testing scored significantly lower on the BOTMP than children who completed the testing. The inclusion of these students, had EQAO results been available, may have strengthened the observed associations.

Finally, this study was limited in its ability to collect 
information on ethnicity which has been suggested to be a potentially confounding variable by past research.[28] It is important for future researchers to address this limitation and account for variation between different ethnicities.

\section{Implications for School Health}

The results of this study have implications for healthy school policy. Past interventions have targeted increasing time spent in physical education classes in an effort to positively impact academic performance. $[5,6]$ These results reaffirm that children with higher levels of aerobic capacity demonstrate better academic performance, supporting policies to increase physical activity opportunities during the school day. Additionally, these results emphasize the importance of physical education in the school curriculum.
The results of the current study also suggest that interventions geared towards improving academic performance need to consider motor proficiency evaluation as an important component. Estimates of the prevalence of children with significant motor competence issues range between five and eight percent representing a sizable number of children at risk for poor academic performance.[11] Since motor proficiency has a positive relationship with academic performance, it is important to explore interventions to enhance the motor proficiency of children displaying difficulty.

\section{Human Subjects Approval Statement}

The PHAST study was given clearance by the Research Ethics Boards of both Brock University and the District School Board of Niagara.

\section{Appendices}

Table 1. Sample Characteristics by Sex

\begin{tabular}{|c|c|c|}
\hline Variable & $\begin{array}{c}\text { Female Subjects (N=926) } \\
\text { Mean (SD) }\end{array}$ & $\begin{array}{c}\text { Male Subjects (N=938) } \\
\text { Mean (SD) }\end{array}$ \\
\hline Age (yrs.) & $11.90(0.32)$ & $11.92(0.35)$ \\
\hline VO $_{2}$ peak $\left(\mathbf{m l}^{\prime} \mathbf{m i n}^{-1} \cdot \mathbf{k g}^{-1}\right)$ & $43.92(4.52)$ & $46.09(5.72)^{* *}$ \\
\hline BOTMP (percentile) & $63.18(30.20)$ & $71.93(28.87)^{* *}$ \\
\hline EQAO Math & $3.08(0.63)$ & $3.13(0.67)$ \\
\hline EQAO Writing & $3.29(0.53)$ & $3.01(0.51)^{* *}$ \\
\hline EQAO Reading & $3.21(0.63)$ & $3.05(0.64)^{* *}$ \\
\hline EQAO Average & $3.19(0.52)$ & $3.06(0.52)^{* *}$ \\
\hline
\end{tabular}

** T-test reveals $\mathrm{p}<.0001$ between sex

Table 2. Hierarchical Linear Modeling of EQAO Average on Age, Sex, Motor Proficiency, Aerobic Fitness, and Parental Education

\begin{tabular}{|c|c|c|c|}
\hline Fixed Effects & $\begin{array}{c}\text { Model 1 } \\
\text { Estimate (SE) }\end{array}$ & $\begin{array}{c}\text { Model 2 } \\
\text { Estimate (SE) }\end{array}$ & $\begin{array}{c}\text { Model 3 } \\
\text { Estimate (SE) }\end{array}$ \\
\hline Intercept & $3.227(0.398)^{* *}$ & $2.631(0.412)^{* *}$ & $2.309(0.513)^{* *}$ \\
\hline Age & $-0.040(0.033)$ & $-0.033(0.033)$ & $-0.016(0.041)$ \\
\hline Sex & $0.155(0.023)^{* *}$ & $0.175(0.023)^{* *}$ & $0.194(0.028)^{* *}$ \\
\hline Motor Proficiency & $0.004(0.0003)^{* *}$ & $0.003(0.0004)^{* *}$ & $0.002(0.0005)^{* *}$ \\
\hline Aerobic Fitness & - & $0.013(0.002)^{* *}$ & $0.011(0.003)^{*}$ \\
\hline Parental Education & - & - & $0.071(0.008)^{* *}$ \\
\hline Random Effects (school) & & & $0.023(0.006)^{*}$ \\
\hline Intercept & $0.035(0.008)^{* *}$ & $0.023(0.006) *$ & $0.206(0.009)^{* *}$ \\
\hline Residual & $0.223(0.007)^{* *}$ & $0.206(0.009)^{* *}$ & 1179 \\
\hline Sample (n) & 1864 & 1864 & \\
\hline $\begin{array}{r}* \mathrm{p}<.05 \\
* * \mathrm{p}<.0001\end{array}$ & & &
\end{tabular}




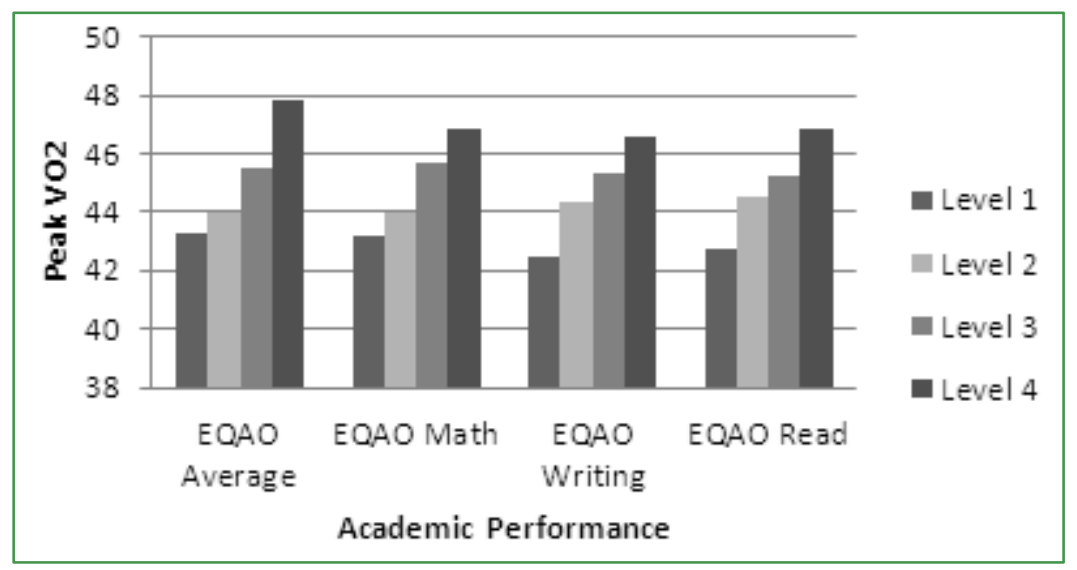

Figure 1. Peak $\mathrm{VO}_{2}$ by EQAO Subject Area and Score

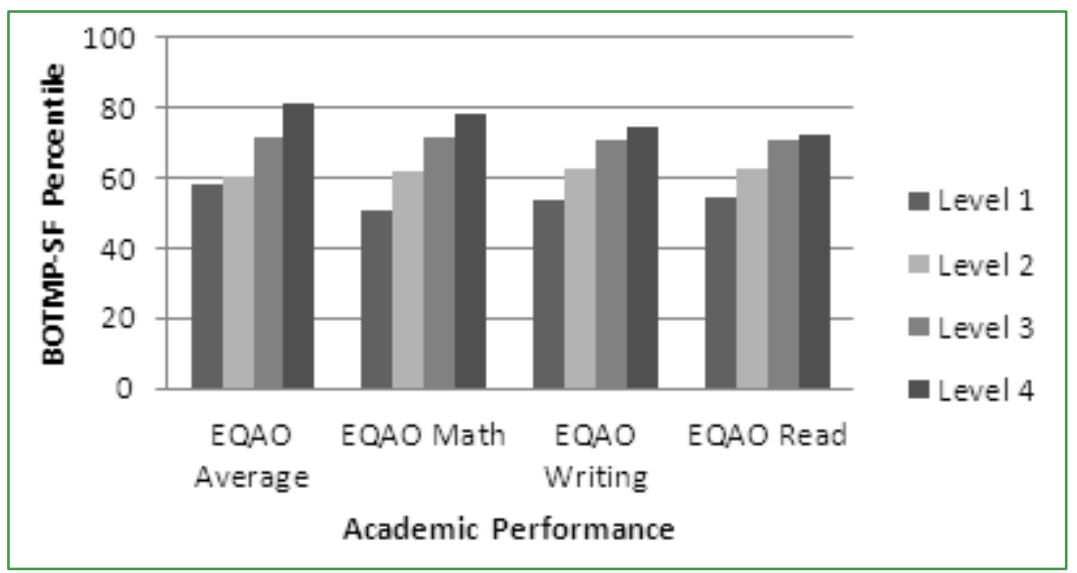

Figure 2. BOTMP Percentile by EQAO Subject Area and Score

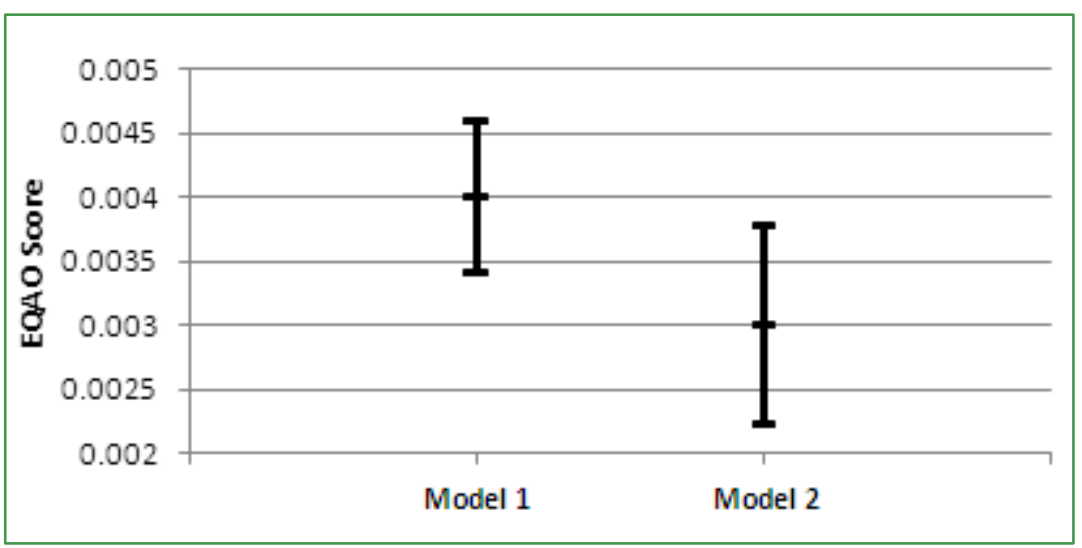

Figure 3. Confidence Intervals (95\%) Slope of Motor Proficiency

\section{REFERENCES}

[1] Van Sluijs EMF, McMinn AM, Griffin SJ. Effectiveness of interventions to promote physical activity in children and adolescents: systematic review of controlled trials. $B M J$. 2007;335(7622):703-705.

[2] Ontario Ministry of Education. Policy / memorandum no.
138. Available at

http://www.edu.gov.on.ca/extra/eng/ppm/138.html. Accessed June 1, 2012.

[3] Kantomaa MT, Tammelin TH, Demakakos P, Ebeling HE, Taanila AM. Physical activity, emotional and behavioural problems, maternal education and self-reported educational performance of adolescents. Health Educ Res. 2010;25(2):368-379.

[4] Sigfúsdóttir ID, Kristjánsson ÁL, Allegrante JP. Health behaviour and academic achievement in Icelandic school 
children. Health Educ Res. 2007;22(1):70-80.

[5] Sallis JF, McKenzie TL, Kolody B, Lewis M, Marshall S, Rosengard P. Effects of health-related physical education on academic achievement: project SPARK. Res Q Exerc Sport. 1999;70(2):127-134.

[6] Ahamed Y, MacDonald H, Reed K, Naylor PJ, Liu-Ambrose T, McKay H. School-based physical activity does not compromise children's academic performance. Med Sci Sports Exerc. 2007;39(2):371-376.

[7] Blair SN, Cheng Y, Holder JS. Is physical activity or physical fitness more important in defining health benefits? Med Sci Sports Exerc. 2001;33(6):s379-s399.

[8] Chomitz VR, Slining MM, McGowan RJ, Mitchell SE, Dawson GF, Hacker KA. Is there a relationship between physical fitness and academic achievement? Positive results from public school children in northeastern United States. $J$ Sch Health. 2009;79(1):30-37.

[9] Van Dusen DP, Kelder SH, Kowhl HW, Ranjit N, Perry CL. Associations of physical fitness and academic performance among schoolchildren. $J$ Sch Health. 2011;81(12):733-740.

[10] Colley RC, Garriguet D, Janssen I, Craig CL, Clarke J, Tremblay MS. Physical activity of Canadian children and youth: accelerometer results from the 2007 to 2009 Canadian health measures survey. Health Rep. 2011;22(1):15-23.

[11] Barnhart RC, Davenport MJ, Epps SB, Nordquist VM. Developmental coordination disorder. Phys Ther. 2003;83(8):722-731.

[12] Cairney J, Hay JA, Faught BE, Wade TJ, Corna L, Flouris A. Developmental coordination disorder, generalized self-efficacy toward physical activity, and participation in organized and free play activities. $J$ Pediatr. 2005;147(4):515-520.

[13] Wrotniak BH, Epstein LH, Dorn JM, Jones KE, Kondilis VA. The relationship between motor proficiency and physical activity in children. Pediatrics. 2006;118(6):e1758-e1765.

[14] Silman A, Cairney J, Hay JA, Klentrou P, Faught BE. Role of physical activity and perceived adequacy on peak aerobic power in children with developmental coordination disorder. Hum Mov Sci. 2011;30(3):672-681.

[15] Rivilis I, Hay JA, Cairney J, Klentrou P, Liu J, Faught BE. Physical Activity and Fitness in Children with Developmental Coordination Disorder: A Systematic Review. Res Dev Disabil. 2011;32(3):894-910.

[16] Wocadlo C, Rieger I. Motor impairment and low achievement in very preterm children at eight years of age. Early Hum Dev. 2008;84(11):769-776.

[17] Dewey D, Kaplan BJ, Crawford SG, Wilson BN. Developmental coordination disorder: associated problems in attention, learning, and psychosocial adjustment. Hum Mov Sci. 2002;21(5):905-918.

[18] Cairney J, Hay JA, Veldhuizen S, Missiuna C, Mahlberg N, Faught BE. Trajectories of relative weight and waist circumference among children with and without developmental coordination disorder. CMAJ. 2010;182(11):1167-1172

[19] Statistics Canada. 2006 community profiles. Available at http://www12.statcan.ca/census-recensement/2006/dp-pd/pro f/92-591/index.cfm. Accessed June 1, 2012.

[20] Education Quality and Accountability Office. How final scores are calculated. Available at http://www.eqao.com/Test/G6/Scores.aspx?Lang=E. Accessed June 1, 2012.

[21] Bruininks R. Bruininks-Oseretsky Test of Motor Proficiency. American Guidance Service, Circle Pines, MI, USA; 1978.

[22] Cairney J, Hay JA, Veldhuizen S, Missiuna C, Faught BE. Comparing probable case identification of developmental coordination disorder using the short form of the Bruininks-Oseretsky test of motor proficiency and the movement ABC. Child Care Health Dev. 2009;35(3):402-408.

[23] Losse A, Henderson SE, Elliman D, Hall D, Knight E, Jongmans M. Clumsiness in children - do they grow out of it? A 10-year follow-up study. Dev Med Child Neurol. 1991;33(1):55-68.

[24] Léger LA, Lambert J. A maximal multistage 20-m shuttle run test to predict $\mathrm{VO}_{2}$ max. Eur $J$ Appl Physiol. 1982;49(1):1-12.

[25] Van Mechelen W, Hlobil H, Kemper HCG. Validation of two running tests as estimates of maximal aerobic power in children. Eur J Appl Physiol. 1986;55(5):503-506.

[26] Armstrong, N. Physical fitness and physical activity during childhood and adolescence. Champaign, IL: Human Kinetics. 1998.

[27] Léger LA, Mercier D, Gadoury C, Lambert J. The multistage 20 metre shuttle run test for aerobic fitness. J Sports Sci. 1988;6(2):93-101.

[28] Patterson CJ, Kupersmidt JB, Vaden NA. Income level, gender, ethnicity, and household composition as predictors of children's school-based competence. Child Dev. 1990;61(2):485-494.

[29] Toutkoushian RK, Curtis T. Effects of socioeconomic factors on public high school outcomes and rankings. $J$ Educ Res. 2005;98(5):259-271.

[30] Krull JL, MacKinnon DP. Multilevel modeling of individual and group level mediated effects. Multi Behav Res. 2001;36(2):249-277.

[31] Rosenblum S, Livneh-Zirinski M. Handwriting process and product characteristics of children diagnosed with developmental coordination disorder. Hum Mov Sci. 2008;27(2):200-214.

[32] Feder KP, Majnemer A. Handwriting development, competency, and intervention. Dev Med Child Neurol. 2007;49(4):312-317.

[33] Piek JP, Pitcher TM, Hay DA. Motor coordination and kinaesthesis in boys with attention deficit-hyperactivity disorder. Dev Med Child Neurol. 1999;41(3):159-165.

[34] Tseng MH, Henderson A, Chow SMK, Yao G. Relationship between motor proficiency, attention, impulse, and activity in children with ADHD. Dev Med Child Neurol. 2004;46(6):381-388.

[35] Barry TD, Lyman RD, Klinger LG. Academic 
underachievement and attention-deficit hyperactivity disorder: The negative impact of symptom severity on school performance. $J$ Sch Psychol. 2002;40(3):259-283.

[36] Loe IM, Feldman HM. Academic and educational outcomes of children with ADHD. $J$ Pediatr Psychol. 2007;32(6):643-654.

[37] Wentzel KR, Wigfield A. Academic and social motivational influences on students' academic performance. Educ Psychol
Rev. 1998;10(2):155-175.

[38] Smyth MM, Anderson HI. Coping with clumsiness in the school playground: social and physical play in children with coordination impairments. $\mathrm{Br} J$ Dev Psychol. 2000;18(3):389-413.

[39] Poulsen AA, Ziviani JM, Cuskelly M, Smith R. Boys with developmental coordination disorder: loneliness and team sports participation. Am J Occup Ther. 2007;61(4):451-462. 